\title{
Dynamic study of bismuth telluride quantum dot assisted titanium oxide for efficient photoelectrochemical performance
}

\author{
Pallavi B. Patil, Vijay V. Kondalkar, Kishorkumar V. Khot, Chaitali S. Bagade, Rahul M. Mane, P. N. Bhosale* \\ Materials Research Laboratory, Department of Chemistry, Shivaji University, Kolhapur-416004, India \\ *p_n_bhosale@rediffmail.com
}

PACS 82.45 Mp

DOI 10.17586/2220-8054-2016-7-4-604-608

\begin{abstract}
The $3 \mathrm{D} \mathrm{TiO}_{2}$ microflowers, sensitized by $\mathrm{Bi}_{2} \mathrm{Te}_{3}$ nanoparticles, having novel architecture were generated employing a two-step synthetic strategy, including a hydrothermal process and a potentiostatic electrodeposition technique. The design and synthesis of quantum dots (QDs) for achieving high photoelectrochemical performance is an urgent need for high technology fields
\end{abstract}

Keywords: $\mathrm{Bi}_{2} \mathrm{Te}_{3}$ QDs assisted $\mathrm{TiO}_{2}, 1 \mathrm{D}$ nanorods, PEC.

Received: 30 January 2016

Revised: 6 May 2016

\section{Introduction}

Quantum dot-sensitized solar cells (QDSCs) have received much attention because they are promising candidates for low cost and large area photovoltaic applications. Semiconductor quantum dot-sensitized solar cells (QDSSCs) have the advantages of being low cost and a simple fabrication process. The most attractive property of a semiconductor quantum dot is its ability to promote the photoconversion efficiency above Shockley-Queisser limit. The low efficiency of QDSSCs is attributed to the relatively low photovoltage in the cell compared to DSSCs and to the recombination paths induced by the electronic properties of the interfaces formed at $\mathrm{TiO}_{2}-\mathrm{QD}-$ electrolyte triple junction [1]. Secondly, it is difficult to incorporate QDs into a $\mathrm{TiO}_{2}$ mesoporous matrix to obtain a well-covered QD monolayer on the inner surface of the $\mathrm{TiO}_{2}$ electrode. Other possible reasons include QDelectrolyte interfaces [2], electron loss occurring through charge recombination at the $\mathrm{TiO}_{2}$-electrolyte interface [3]. To achieve higher performance photovoltaic solar cells, morphologies and structures of anode materials are also widely investigated [4]. In general, mesoporous $\mathrm{TiO}_{2}$ nanoparticles are the most frequently used photoanodes in DSSCs and QDSSCs, due to their high internal surface area for sufficient sensitizer anchoring [5]. Unfortunately, mesoporous $\mathrm{TiO}_{2}$ nanoparticles have some disadvantages, such as charge collection rate due to surface states and grain boundaries existing in the pathway of nanoparticles, which can lead to many unexpected trapping and detrapping, and thus, inferior light scattering [6]. In this study, we successfully synthesized vertically aligned $\mathrm{TiO}_{2}$ nanorods sensitized by $\mathrm{Bi}_{2} \mathrm{Te}_{3}$ nanoparticles. The photoelectrochemical performance of $\mathrm{TiO}_{2}$ is greatly improved by sensitization of $\mathrm{TiO}_{2}$ by $\mathrm{Bi}_{2} \mathrm{Te}_{3}$ nanoparticles [7]. The sensitization of $\mathrm{TiO}_{2}$ by $\mathrm{Bi}_{2} \mathrm{Te}_{3}$ nanoparticles leads to a separation of the charge carriers. The charge separation leads to a reduction in the overall recombination in the solar cells and the enhancement of photogenerated carrier collection.

\section{Method}

First, $\mathrm{TiO}_{2}$ can be prepared by our previously-reported hydrothermal method [7]. In detail $0.04 \mathrm{M}$ TTIP was added in the solution containing $3 \mathrm{M} \mathrm{HCl}$ and ethylene glycol stirred for some time. The clear transparent solution then poured into a Teflon-lined stainless steel autoclave maintained at $160^{\circ} \mathrm{C}$ for $2 \mathrm{~h}$. The electrodeposition of $\mathrm{Bi}_{2} \mathrm{Te}_{3}$ nanoparticles on $\mathrm{TiO}_{2}$ thin films was accomplished in a three electrode cell configuration containing aqueous solutions of $7 \mathrm{mM} \mathrm{Bi}\left(\mathrm{NO}_{3}\right)_{3}$ and $10 \mathrm{mM}$ Te in $1 \mathrm{M} \mathrm{HNO}_{3}$. The deposition was carried out at $-0.8 \mathrm{~V}$ vs $\mathrm{Ag} / \mathrm{AgCl}$. In this, $\mathrm{TiO}_{2}$ nanorods act as working electrode, platinum as counter electrode and $\mathrm{Ag} / \mathrm{AgCl}$ as reference electrode. The deposition time was fixed at $30 \mathrm{~min}$. and the depositions were carried out at room temperature. In order to control the size of $\mathrm{Bi}_{2} \mathrm{Te}_{3}$ nanoparticles and prevent large particle formation, PVA was used as structure directing agent. 


\section{Results and discussion}

\subsection{Optical absorption spectra of $\mathrm{Bi}_{2} \mathrm{~T}_{3}$ loaded $\mathrm{TiO}_{2}$}

The light absorption properties of $\mathrm{Bi}_{2} \mathrm{Te}_{3}$-loaded $\mathrm{TiO}_{2}$ thin was evaluated using the UV-visible spectrophotometer (Shimadzu UV-1800 Japan). Figure 1 shows the Tauc plot of $\mathrm{Bi}_{2} \mathrm{Te}_{3}$ loaded $\mathrm{TiO}_{2}$ thin films. The band gap energy of composite can be expressed by the Tauc relation. It is well known that there are fundamental optical transitions, namely directly-allowed $(n=1 / 2)$ and indirectly-allowed $(n=2)$ transition. It is also noteworthy that the band gap energy of $\mathrm{Bi}_{2} \mathrm{Te}_{3}$ loaded $\mathrm{TiO}_{2}$ heterostructures was found to be $2.1 \mathrm{eV}$, indicating the optical absorption of the hybrid nanostructure has been extended from the UV region to the visible region.

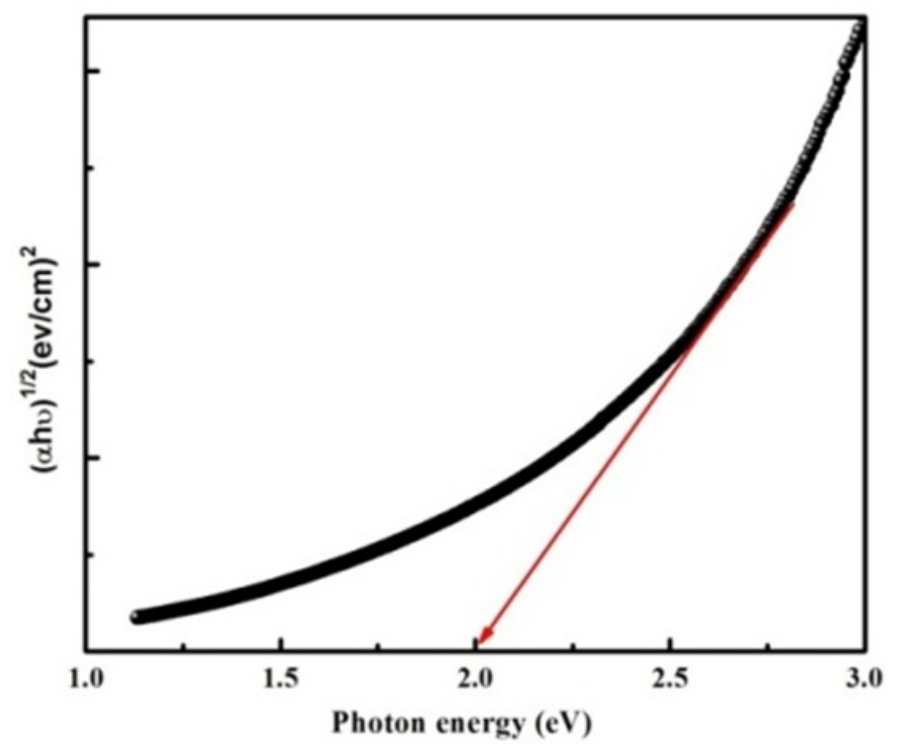

FIG. 1. Optical absorption spectra of $\mathrm{Bi}_{2} \mathrm{Te}_{3}$ loaded $\mathrm{TiO}_{2}$ thin film

\subsection{X-ray diffraction (XRD) pattern of $\mathrm{Bi}_{2} \mathrm{~T}_{3}$ loaded $\mathrm{TiO}_{2}$ thin film}

The strong characteristic diffraction peak appeared at around $27.70^{\circ}$ corresponds to (110) peak associated with rutile phase of $\mathrm{TiO}_{2}$ (Space Group: P42/ mnm, JCPDS: 00-001-0562) (Rigaku, D/MAX Ultima III XRD spectrometer (Japan)). Furthermore, it should be noted that diffraction peak appearing at $27.67^{\circ}$ corresponds to the (015) plane of Rhombohedral $\mathrm{Bi}_{2} \mathrm{Te}_{3}$ (JCPDS: 15-0863 space group $\mathrm{R}-3 \mathrm{~m}$ ) shown in Fig. 2. Due to overlap between (110) plane of $\mathrm{TiO}_{2}$ and (015) plane of $\mathrm{Bi}_{2} \mathrm{Te}_{3}$, it is difficult to distinguish these two peaks in the XRD pattern. While the other peaks appeared at $2 \theta 27.70^{\circ}, 36.22^{\circ}, 41.35^{\circ}, 54.58^{\circ}, 56.97^{\circ}$ and $65.54^{\circ}$, corresponding to the (110), (101), (111), (211), (220) and (221) crystal plane of tetragonal $\mathrm{TiO}_{2}$ and $27.67^{\circ}, 37.86^{\circ}, 62.91^{\circ}$ and $69.91^{\circ}$ corresponding to the (015), (1010), (0213) and (0216) crystal planes of rhombohedral $\mathrm{Bi}_{2} \mathrm{Te}_{3}$.

It was found that the diffraction peak of the resulting deposit confirms the successful loading of $\mathrm{Bi}_{2} \mathrm{Te}_{3}$ nanoparticles on $\mathrm{TiO}_{2}$. The crystallite size of the material was calculated by using Debye Scherrer formula, given in equation 1:

$$
D=\frac{0.94 \lambda}{\beta \cos \theta},
$$

where $D$ is crystallite size, $\theta$ is Peak position of X-ray diffraction, $\beta$ is Full Width at Half Maxima (FWHM) in radian, $\lambda$ is Wavelength of X-ray used $(0.154 \mathrm{~nm})$. The XRD parameters are summarized in Table 1.

TABLE 1. XRD parameters.

\begin{tabular}{|c|c|c|c|}
\hline Sample & $\begin{array}{c}\text { Crystallite } \\
\text { Size (D) }(\mathrm{nm})\end{array}$ & $\begin{array}{c}\text { Microstrain }(\varepsilon) \\
10^{-3}\left(\text { lines } \mathrm{m}^{-2}\right)\end{array}$ & $\begin{array}{c}\text { Dislocation density } \\
(\delta) \times 10^{-3}\left(\text { lines }^{-2} \mathrm{~m}^{-4}\right)\end{array}$ \\
\hline $\mathrm{Bi}_{2} \mathrm{Te}_{3}$ loaded $\mathrm{TiO}_{2}$ & 16.78 & 20156 & 3.5515 \\
\hline
\end{tabular}




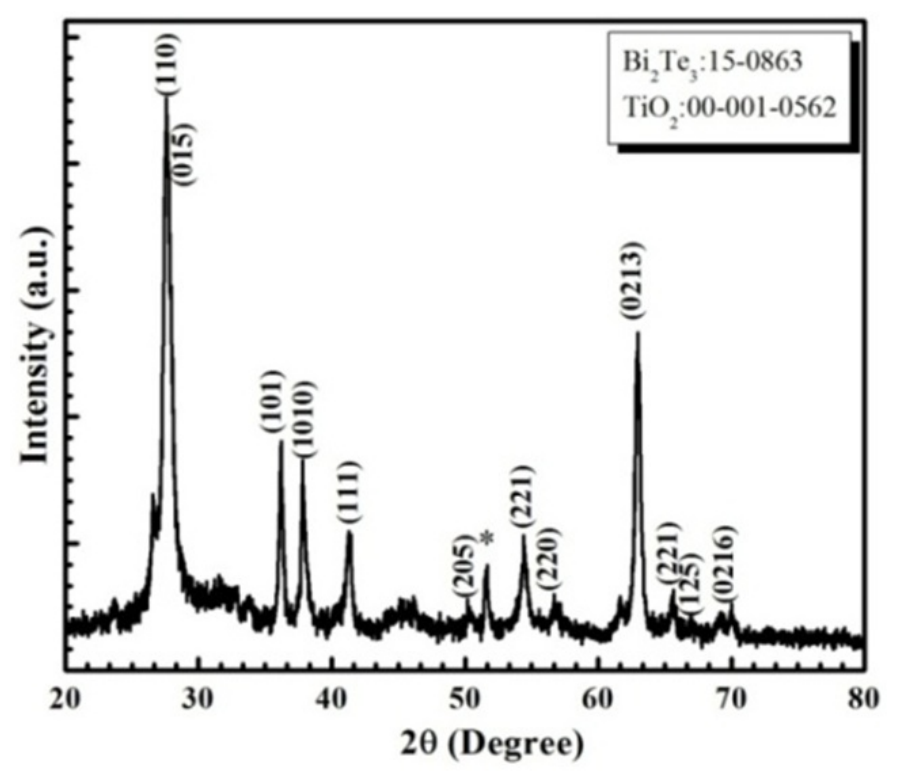

FIG. 2. X-ray diffraction pattern of $\mathrm{Bi}_{2} \mathrm{Te}_{3}$ loaded $\mathrm{TiO}_{2}$ thin film

\subsection{Field Emission Scanning Electron Microscopy (FESEM) of $\mathrm{Bi}_{2} \mathrm{~T}_{3}$ loaded $\mathrm{TiO}_{2}$ thin film}

The morphological analysis of the synthesized material was carried out using field emission scanning electron microscopy (FESEM) (Hitachi, S-4700). Fig. 3 shows the low and high magnification field emission scanning electron microscopy (FESEM) images. The FESEM image shows that entire surface of FTO substrate is covered with well-aligned $\mathrm{TiO}_{2}$ nanorods coated with $\mathrm{Bi}_{2} \mathrm{Te}_{3}$ nanoparticles. From the higher magnification of such nanorod arrays, the average diameter of the $\mathrm{TiO}_{2}$ nanorod is $95-110 \mathrm{~nm}$.

After $\mathrm{Bi}_{2} \mathrm{Te}_{3}$ quantum dot loading, the $\mathrm{TiO}_{2}$ nanorods become rough, which means that the QDs have been successfully deposited on the surface of the $\mathrm{TiO}_{2}$ nanorods after potentiostatic electrodeposition. The vertical alignment of the $\mathrm{TiO}_{2}$ nanorods is beneficial for the improvement in the charge transfer of the solar cells. Such deep penetration of $\mathrm{Bi}_{2} \mathrm{Te}_{3}$ nanoparticles into the $\mathrm{TiO}_{2}$ nanorods improves the charge separation and reduces recombination rate, which is beneficial for the photoelectrochemical performance of the solar cell.

\subsection{Compositional analysis $\mathrm{Bi}_{2} \mathrm{Te}_{3}$ loaded $\mathrm{TiO}_{2}$ thin film}

Qualitative and quantitative analysis of the prepared $\mathrm{Bi}_{2} \mathrm{Te}_{3}$ loaded $\mathrm{TiO}_{2}$ was carried out using energy dispersive X-ray spectroscopy (EDS).

The EDS spectrum confirms the presence of titanium, oxygen, bismuth and tellurium in prepared $\mathrm{Bi}_{2} \mathrm{Te}_{3}$ loaded $\mathrm{TiO}_{2}$ thin film. From Figure 4, it is readily seen that the peaks at 4.5, 0.5, 2.4 and $3.7 \mathrm{keV}$ confirm the presence of $\mathrm{Ti}, \mathrm{O}, \mathrm{Bi}$ and $\mathrm{Te}$ respectively in the $\mathrm{Bi}_{2} \mathrm{Te}_{3}$-loaded $\mathrm{TiO}_{2}$ film.

\subsection{Photoelectrochemical performance (PEC)}

The typical J-V characteristic curve of $\mathrm{Bi}_{2} \mathrm{Te}_{3}$-loaded $\mathrm{TiO}_{2}$ thin film was determined. The photoelectrochemical performance of the $\mathrm{Bi}_{2} \mathrm{Te}_{3}$-loaded $\mathrm{TiO}_{2}$ thin film was carried out using a two electrode cell configuration (AUTOLAB PGSTAT100 FRA 32 potentiostat). In order to evaluate the photoelectrochemical performance, the $\mathrm{Bi}_{2} \mathrm{Te}_{3}$-loaded $\mathrm{TiO}_{2}$ thin film acts as a photoanode, graphite as counter electrode with 0.5 polysulfide electrolyte. The cell configuration is as follows: Glass/ $\mathrm{FTO} / \mathrm{Bi}_{2} \mathrm{Te}_{3}$ loaded $\mathrm{TiO}_{2} / 0.5 \mathrm{M}$ Polysulphide/G .

The photoelectrochemical performance i.e. fill factor (FF) and overall light to electric energy conversion efficiency (\%) was calculated by equation (2) and (3):

$$
\begin{gathered}
F F=\frac{V_{\max } J_{\max }}{V_{o c} J_{s c}} \\
\eta_{\%}=\frac{V_{o c} J_{s c}}{P_{i n} \times F F \times 100,}
\end{gathered}
$$

where $V_{o c}$ is open circuit voltage, $J_{s c}$ is short circuit current, $V_{\max }$ is maximum voltage, $J_{\max }$ is maximum current, FF is the fill factor and $P_{i n}$ is the intensity of the incident light. 

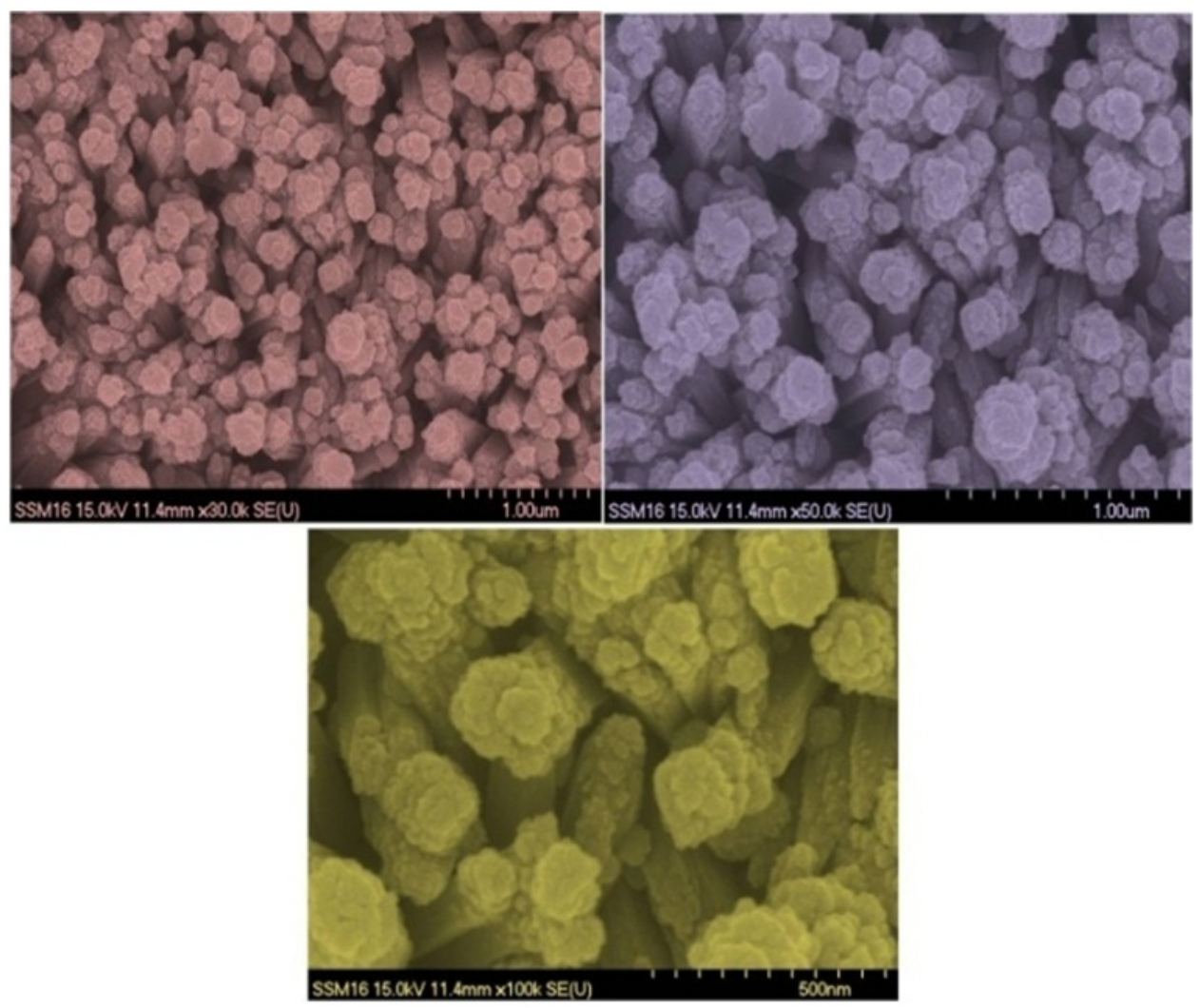

FIG. 3. Field emission scanning electron microscopy images of $\mathrm{Bi}_{2} \mathrm{Te}_{3}$ loaded $\mathrm{TiO}_{2}$ thin film

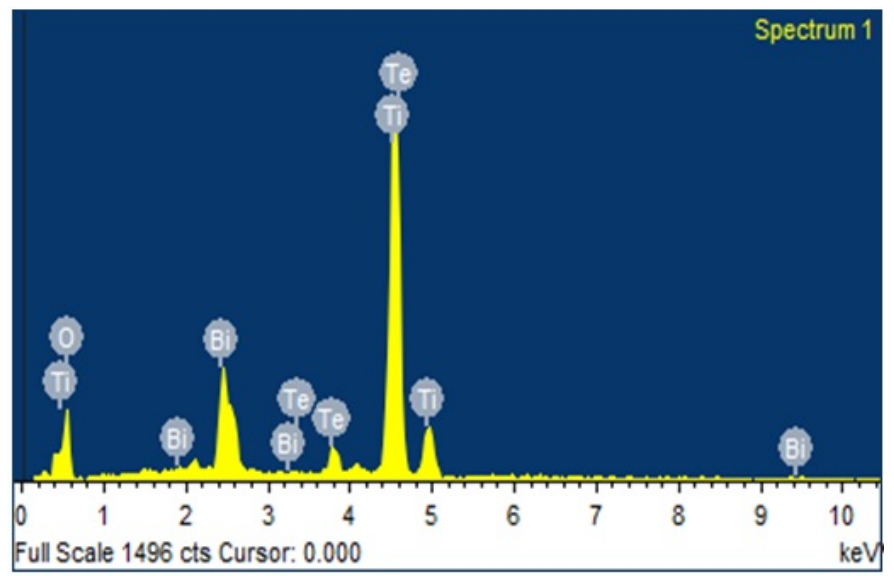

FIG. 4. EDS spectrum of $\mathrm{Bi}_{2} \mathrm{Te}_{3}$ loaded $\mathrm{TiO}_{2}$ thin film

The detailed photovoltaic parameters are summarized in Table 2. The $\mathrm{Bi}_{2} \mathrm{Te}_{3}$-loaded $\mathrm{TiO}_{2}$ thin film shows $0.026 \%$ photoconversion efficiency.

TABLE 2. Photoelectrochemical solar cell parameters of $\mathrm{Bi}_{2} \mathrm{Te}_{3}$ loaded $\mathrm{TiO}_{2}$ thin film

\begin{tabular}{|c|c|c|c|c|c|}
\hline Electrode & $\begin{array}{c}V_{o c} \\
(\mathrm{mV})\end{array}$ & $\begin{array}{c}J_{s c} \\
\left(\mu \mathrm{A} / \mathrm{cm}^{2}\right)\end{array}$ & $\begin{array}{c}R_{s} \\
(\Omega)\end{array}$ & $\begin{array}{c}R_{s h} \\
(\Omega)\end{array}$ & $\eta_{\%}$ \\
\hline $\mathrm{Bi}_{2} \mathrm{Te}_{3}$ loaded $\mathrm{TiO}_{2}$ & 397.03 & 61 & 2660 & 4762 & 0.026 \\
\hline
\end{tabular}




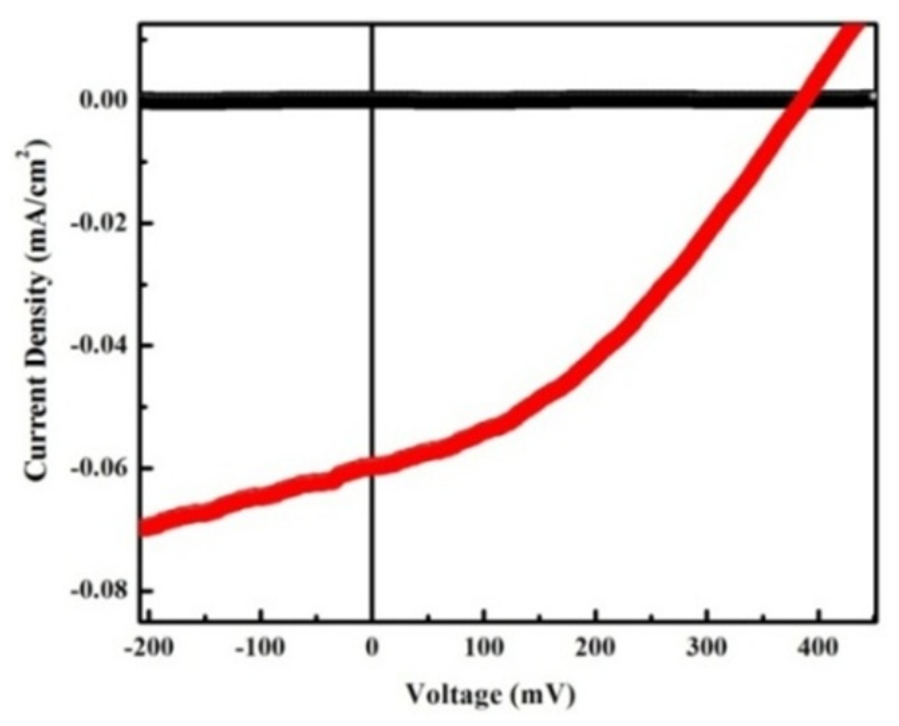

FIG. 5. J-V characteristic curve of $\mathrm{Bi}_{2} \mathrm{Te}_{3}$ loaded $\mathrm{TiO}_{2}$ thin film

\section{Conclusion}

In summary, a $\mathrm{Bi}_{2} \mathrm{Te}_{3}$-loaded $\mathrm{TiO}_{2}$ thin film was successfully prepared by a two-step synthetic strategy. 1D nanorods provided a unidirectional transport path for efficient charge, leading to high photoelectrochemical performance. Therefore, this novel combinatorial $\mathrm{Bi}_{2} \mathrm{Te}_{3}$ loaded $\mathrm{TiO}_{2}$ thin film shows $0.026 \%$ photoconversion efficiency.

\section{References}

[1] Sero I., Gimenez S., Santiago F., Gomez R, Shen Q., Toyoda T., Bisquert J. Recombination in Quantum Dot Sensitized Solar Cells, Acc. Chem. Res., 2009, 42, P. 1848-1857.

[2] Diguna L., Murakami M., Sato A., Kumagai Y., Ishihara T., Kobayashi N., Shen Q., Toyoda T. Highly efficient CdS/CdSe-sensitized solar cells controlled by the structural properties of compact porous $\mathrm{TiO}_{2}$ photoelectrodes. J. Appl. Phys., 2008, 103, P. 084304-084308.

[3] Lee Y., Chang C. Efficient polysulfide electrolyte for CdS quantum dot-sensitized solar cells. J. Power Sources, 2008, 185, P. 584-588.

[4] Wu W., Xu Y., Su C., Kuang D. Ultra-long anatase $\mathrm{TiO}_{2}$ nanowire arrays with multi-layered configuration on FTO glass for high-efficiency dye-sensitized solar cells. Energy Environ. Sci., 2014, 7, P. 644-649.

[5] Shiu J., Lan C., Chang Y., Wu H., Huang W., Diau Eric W. Size-Controlled Anatase Titania Single Crystals with Octahedron-like Morphology for Dye-Sensitized Solar Cells. ACS Nano, 2012, 6, P. 10862-10873.

[6] Du J., Qi J., Wang D., Tang Z., Facile synthesis of Au@ $\mathrm{TiO}_{2}$ core-shell hollow spheres for dye-sensitized solar cells with remarkably improved efficiency. Energy Environ. Sci., 2012, 5, P. 6914-6918.

[7] Patil P., Mali S., Kondalkar V., Mane R., Patil P., Hong C., Bhosale P. Bismuth Telluride quantum dot assisted Titanium Oxide microflowers for efficient photoelectrochemical performance. Mater. Lett., 2015, 159, P. 177-181.

[8] Patil P., Mali S., Kondalkar V., Pawar N., Khot K., Hong C., Patil P., Bhosale P. Single step hydrothermal synthesis of hierarchical $\mathrm{TiO}_{2}$ microflowers with radially assembled nanorods for enhanced photovoltaic performance. RSC Adv, 2014, 4, P. 47278-47286. 